Article

\title{
A Nanostructured Sensor Based on Gold Nanoparticles and Nafion for Determination of Uric Acid
}

\author{
Natalia Stozhko ${ }^{1}$, Maria Bukharinova ${ }^{1}$, Leonid Galperin ${ }^{2}$ and Khiena Brainina ${ }^{1,2, *}$ \\ 1 Ural State University of Economics, 8 Marta St., 62, Yekaterinburg 620144, Russia; sny@usue.ru (N.S.); \\ mbuharinova@mail.ru (M.B.) \\ 2 Ural Federal University, Mira St., 19, Yekaterinburg 620002, Russia; lhalp@k66.ru \\ * Correspondence: baz@usue.ru; Tel.: +7-343-257-2415
}

Received: 18 January 2018; Accepted: 3 March 2018; Published: 6 March 2018

\begin{abstract}
The paper discusses the mechanism of uric acid (UA) electrooxidation occurring on the surface of gold nanoparticles. It has been shown that the electrode process is purely electrochemical, uncomplicated with catalytic stages. The nanoeffects observed as the reduction of overvoltage and increased current of UA oxidation have been described. These nanoeffects are determined by the size of particles and do not depend on the method of particle preparation (citrate and "green" synthesis). The findings of these studies have been used to select a modifier for carbon screen-printed electrode (CSPE). It has been stated that CSPE modified with gold nanoparticles $(5 \mathrm{~nm})$ and $2.5 \%$ Nafion (Nf) may serve as non-enzymatic sensor for UA determination. The combination of the properties of nanoparticles and Nafion as a molecular sieve at the selected $\mathrm{pH} 5$ phosphate buffer solution has significantly improved the resolution of the sensor compared to unmodified CSPE. A nanostructured sensor has demonstrated good selectivity in determining UA in the presence of ascorbic acid. The detection limit of UA is $0.25 \mu \mathrm{M}$. A linear calibration curve has been obtained over a range of $0.5-600 \mu \mathrm{M}$. The $2.5 \% \mathrm{Nf} / \mathrm{Au}(5 \mathrm{~nm}) / \mathrm{CSPE}$ has been successfully applied to determining UA in blood serum and milk samples. The accuracy and reliability of the obtained results have been confirmed by a good correlation with the enzymatic spectrophotometric analysis $\left(R^{2}=0.9938\right)$ and the "added-found" technique (recovery close to $100 \%$ ).
\end{abstract}

Keywords: uric acid; carbon screen-printed electrode; Nafion; gold nanoparticles; nanoeffects; "green" synthesis; milk; blood serum

\section{Introduction}

Uric acid (UA) plays a dual role in the human body: on the one hand, it exhibits antioxidant properties; on the other hand, it causes formation of urates in the tissues in case of purine metabolic disorder. Abnormalities of UA levels are symptoms of Lesch-Nyhan syndrome, multiple sclerosis, cardiovascular, and renal diseases [1,2]. In this regard, monitoring of UA is essential for clinical diagnostics and food analysis.

To determine UA, electrochemical methods are applied. Electrochemical methods have advantages over other methods, as they are more sensitive, selective and can be easily automated. The methods of electrochemical determination of UA in biological liquids (mainly urine) have been developed, but the methods of electrochemical determination of UA in food stuff have not been dealt with so far. Modified glassy carbon electrodes (GCE) are most frequently used for UA determination [3-10]. Its modifying layers can include gold nanoparticles [3,5-10], nanotubes [5,6], reduced graphene oxide [3,7], chitosan [7], Nafion and polymers [4,8], cyclodextrins [9], or their combinations. There are cases of using screen-printed electrodes, modified with single and 
multi-wall carbon nanotubes [11-13], chemically-reduced graphene oxide [14,15], nanoparticles of noble metals [16], or core-shell nanocomposites [17], and enzymes [18,19], in order to determine UA in biological fluids. Unlike GCE, a planar design of screen-printed electrodes enables to use them in portable devices for on-site analysis. Screen-printed electrodes are cheap, as they are manufactured with the use of the technology that provides mass production of transducers with good reproducible characteristics [20]. Significant weaknesses of the exiting modified GCE and screen-printed electrodes, used for UA determination are the following:

- $\quad$ necessity of GCEs surface pretreatment before use;

- time consuming (from several hours $[14,19]$ to several days $[12,17]$ ) procedures of preparing the modifier and modification of the electrode $[5,9,10]$;

- $\quad$ inability to use GCEs in portable devices designed for on-site analysis;

- $\quad$ short lifetime of enzymes, often requiring special storage conditions;

- $\quad$ necessity to preconcentrate analyte (in some cases) [11-13,16,18];

- the use of complex, expensive, non-transportable, malfunctioning flow-injection systems that are difficult to use for on-site analysis [16,18];

- $\quad$ lack of methods of UA electrochemical determination in food products (e.g., milk).

In this regard, it is important to develop a simple enzyme-free screen-printed electrode that does not require any additional operations of separation and concentration, but can be used to determine UA in foods (e.g., milk) and biological objects with a complex matrix, such as blood serum, as the level of UA in blood serum is an essential diagnostic indicator of some diseases.

In our opinion, a practical approach to developing a sensitive and selective UA sensor is the modification of the screen-printed electrode with gold nanoparticles and electrically-conductive perfluorinated membrane (Nafion), which includes a hydrophobic matrix and hydrophilic pores and channels. The reduction of electrode overvoltage and the increase in oxidation currents of compounds diffusing from the solution on the surface of gold nanoparticles [21], together with the ability of Nafion to act as a molecular sieve in multicomponent media, will ensure high analytical and metrological characteristics of the sensor. The combination of nanoparticles and polymer is very practical, as this reduces agglomeration and recrystallization of nanoparticles and results in their fixing on the electrode surface, thereby increasing the stability of the sensor. Selection of $\mathrm{pH}$ medium will improve the resolution sensibility of the sensor.

However, another fundamental issue to be considered in this work is to establish the mechanism of UA electrooxidation on gold nanoparticles. This is due to the existing contradictory views on this issue and to the fact that the earlier proposed approaches and sensors are based on empirical regularities of the processes only. The choice of the modifier and conditions for UA determination should utilize the knowledge of electrode process mechanisms.

The aims of this study are (i) to investigate the type of electrode process for UA oxidation on the nanostructured electrode; (ii) to specify conditions for selective determination of UA in the presence of AA; (iii) to develop a sensor based on carbon screen-printed electrode (CSPE) modified with gold nanoparticles and Nafion, which could be used in portable devices, and (iv) to develop a method of UA determination in blood serum and milk.

Mechanism of Uric Acid Oxidation on a Nanoparticle-Modified Electrode

Some publications look upon UA electrooxidation as an electrocatalytic process, whereby carbon nanotubes/nanoparticle hybrid material [5], restored graphene oxide [14], $\beta$-cyclodextrin [15], and gold nanoparticles $[7,16]$ can act as catalysts.

There are two possible mechanisms for UA electrooxidation:

1. an electrochemical process, without intermediate chemical stages;

2. an electrochemical process, including the catalytic stage, where the formation and decay of intermediate products is expected. 
The interpretation of the process taking place on gold nanoparticles as a process involving the catalytic stage might be problematic.

In order to develop an optimal method of electrochemical determination of UA it may be useful to know the mechanism of the proceeding process. To answer this question, we have used the earlier proposed approach and mathematical model of electrochemical processes, not complicated by chemical stages, but including catalytic stages and nanoeffects [21,22], and have conducted experimental studies.

The mathematical model described in $[21,22]$ was used, which considered electrode processes of various types and nanoeffects. The calculations (results are given below) were performed for the following electrode processes: electrochemical, uncomplicated by other stages (E); electrochemical, including catalytic (EC) stage; and processes with nanoeffects. Equation (1) serves as the basis for these considerations:

$$
i=n F k_{\mathrm{S}} S C_{\mathrm{S}} \exp \left\{\frac{\beta n F\left(E_{\mathrm{in}}-E^{\circ}+v t\right)+\beta \Delta G^{\circ}}{R T}\right\}
$$

where

- $\quad n$, number of electrons involved in the process;

- $\quad F$, Faraday constant $\left(96,485 \mathrm{C} \mathrm{mol}^{-1}\right)$;

- $\quad \beta$, electron transfer coefficient in the anodic phase (0.49 [23]);

- $\quad k_{\mathrm{s}}$, electrode process rate constant $\left(1.00 \times 10^{-4} \mathrm{~cm} \mathrm{~s}^{-1}\right)$, was determined as described earlier [24], using voltammogram of UA oxidation at unmodified GCE;

- $\quad S$, electrode area $\left(\mathrm{cm}^{2}\right)$;

- $\quad C_{\mathrm{s}}$, surface concentration of electroactive substance diffusing to the electrode $\left(\mathrm{mol} \mathrm{cm}^{-3}\right)$;

- $\quad E_{\text {in }}$, initial potential $(0.20 \mathrm{~V})$;

- $\quad E^{\circ}$, redox potential of $\mathrm{UA}$, is given (relative to $\mathrm{Ag} / \mathrm{AgCl}$ ) for red-ox potential in the reaction $\cdot \mathrm{U}^{2-}+\mathrm{e}^{-}+\mathrm{H}^{+} \rightarrow \mathrm{UH}^{2-}$ in accordance with [25] (0.37 V);

- $\quad v$, potential scan rate $\left(\mathrm{V} \mathrm{s}^{-1}\right)$;

- $\quad t$, time (s);

- $\quad R$, universal gas constant $\left(8.314 \mathrm{~J} \mathrm{~mol}^{-1} \mathrm{~K}^{-1}\right)$; and

- $\quad T$, temperature $(\mathrm{K})$.

Gibbs free energy $\left(\Delta G^{\circ}\right)$ was calculated using Equation (2) taken from [21]:

$$
\Delta G^{\circ}=\frac{3 \sigma M}{\rho r}
$$

where

- $\quad \sigma$, surface tension of gold at the air borderline at $700{ }^{\circ} \mathrm{C}(1200 \mathrm{dyn} / \mathrm{cm}[26])$;

- $\quad M$, molar mass of gold $(197 \mathrm{~g} / \mathrm{mol})$;

- $\quad \rho$, density of gold $\left(19.3 \mathrm{~g} / \mathrm{cm}^{-3}\right)$; and

- $\quad r$, radius of nanoparticles.

Figure 1a presents the calculated voltammograms of UA oxidation for $\mathrm{E}$ and EC processes. It is seen that the shape of the voltammogram, describing the EC process with the catalytic stage, has no region of the limiting current. The shape of this voltammogram differs significantly from the shape of the voltammogram illustrating uncomplicated E process.

Figure $1 b, c$ present the calculated voltammograms that were when the electrode $\mathrm{E}$ process included nanoeffects. Nanoeffects are observed as the shift of the voltammograms of the electrodes modified with nanoparticles to the less-positive region, as compared with the unmodified electrode (Figure $1 \mathrm{~b}$ ). The smaller the size of the nanoparticles, greater the nanoeffects. If the surface area of nanoparticles of various sizes is almost the same as the electrode area, then the currents of UA oxidation on these nanoparticles will be commensurable (Figure 1b). Figure 1c illustrates the calculated 
voltammograms of UA oxidation on gold nanoparticles $(3 \mathrm{~nm})$ with different surface areas. In one case, the area of nanoparticles was limited by the size equal to the GCE area $\left(S=4.5 \times 10^{-2} \mathrm{~cm}^{2}\right)$. In the other case, the real total surface area of nanoparticles $\left(S=8.3 \times 10^{-2} \mathrm{~cm}^{2}\right)$ was used for the calculations. A significant increase in the UA oxidation current was observed on the nanoparticles with a larger, than the limited area, surface area. Thus, nanoeffects are demonstrated in the decrease in the overvoltage and the increase in the UA oxidation current.
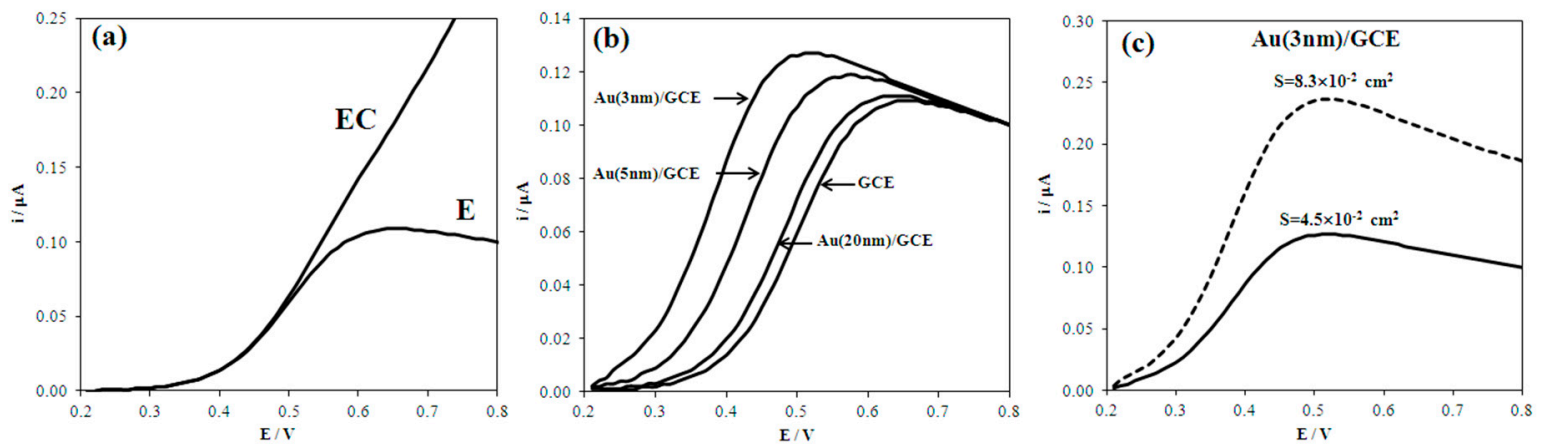

Figure 1. Calculated anodic voltammograms of $0.02 \mathrm{mM}$ UA for different electrode processes: (a) electrochemical (E) and electrochemical, including catalytic stage (EC) at GCE; (b) electrochemical process at GCE, $\mathrm{Au}(20 \mathrm{~nm}) / \mathrm{GCE}, \mathrm{Au}(5 \mathrm{~nm}) / \mathrm{GCE}, \mathrm{Au}(3 \mathrm{~nm}) / \mathrm{GCE}$ with equal surface area $S=4.5 \times$ $10^{-2} \mathrm{~cm}^{2}$; and (c) electrochemical process at $\mathrm{Au}(3 \mathrm{~nm}) / \mathrm{GCE}$ with different nanoparticle surface.

\section{Experimental}

\subsection{Chemicals and Apparatus}

$\mathrm{HCl}$ (NevaReactiv, Saint Petersburg, Russia), $\mathrm{HAuCl}_{4}$ (Tom'analit, Tomsk, Russia), sodium citrate (Himreactivsnab, Ufa, Russia), Nafion (Fluka, Buchs, Switzerland), ascorbic acid (Sigma, Shanghai, China), uric acid (Acros Organics, Geel, Belgium), glucose (NevaReactiv, Saint Petersburg, Russia), urea (Fluka, Buchs, Switzerland), L-tryptophan (AppliChem, Darmstadt, Germany), and creatinine (Merc, Darmstadt, Germany) were used. Phosphate buffer solutions (PBS) were used as supporting electrolytes. All chemicals were of extra pure grade and chemically pure grade.

A semi-automatic computerized voltammetric analyzer IVA-5 (IVA, Yekaterinburg, Russia) with a PE-6100 magnetic stirrer and a three-electrode electrochemical cell was employed for voltammetric measurements. Working electrodes were glassy carbon electrode (GCE) (Metrohm, Herisau, Switzerland), gold disk electrode (Au-bulk) (Metrohm, Herisau, Switzerland) and carbon screen-printed electrode (CSPE) (IVA, Yekaterinburg, Russia). A glassy carbon rod and Ag/ AgCl (saturated with $\mathrm{KCl}$ ) were used as the auxiliary electrode and reference electrode, respectively.

\subsection{Synthesis and Characterisation of Gold Nanoparticles}

Gold suspension was synthesized by chemical reduction of aqueous solution of chloroauric acid $\left(\mathrm{HAuCl}_{4}\right)$ by sodium citrate $\left(\mathrm{Na}_{3} \mathrm{C}_{6} \mathrm{H}_{5} \mathrm{O}_{7}\right)$ in accordance with the standard Turkevich method and as described in [21]. The gold particles of different sizes were prepared by changing the ratio $\mathrm{C}\left(\mathrm{HAuCl}_{4}\right): \mathrm{C}\left(\mathrm{Na}_{3} \mathrm{C}_{6} \mathrm{H}_{5} \mathrm{O}_{7}\right)$. Two samples of gold sol $\mathrm{Au}_{\text {red }}$ and $\mathrm{Au}_{\text {vio }}$ were obtained with the ratio $\mathrm{C}\left(\mathrm{HAuCl}_{4}\right): \mathrm{C}\left(\mathrm{Na}_{3} \mathrm{C}_{6} \mathrm{H}_{5} \mathrm{O}_{7}\right)$ equal to $1: 5$ and 1:2, respectively.

"Green" nanoparticles were obtained using Hippóphaë extract. To prepare it, $0.4 \mathrm{~g}$ of powdered dry Hippóphaë leaves were placed in a beaker, then $10 \mathrm{~mL}$ of water was added and mixed for 15 min at room temperature. The solid phase was separated by centrifugation at 10,000 rpm and the liquid phase was used to synthesize nanoparticles.

During "green" synthesis of gold nanoparticles, $250 \mu \mathrm{L}$ of freshly-prepared Hippóphaë extract was added to $5 \mathrm{~mL}$ of a boiling solution of $2 \times 10^{-3} \mathrm{M} \mathrm{HAuCl}_{4}$ and the mixture was intensively stirred. 
TEM images of gold sols are given in our previous paper [21]. The gold particles with the radius of 5, 14, and $20 \mathrm{~nm}$ prevailed in sols $\mathrm{Au}_{\mathrm{red}}$, $\mathrm{A} u_{\text {green, }}$ and $\mathrm{Au} \mathrm{u}_{\mathrm{vio}}$, respectively.

\subsection{Preparation of Modified Electrodes}

CSPE or GCE as substrates and gold nanoparticles suspensions (5, 14, $20 \mathrm{~nm}$ ) were used to modify electrodes.

The drop casting method was used to modify CSPE: $5 \mu \mathrm{L}$ of gold nanoparticles suspension was deposited on the CSPE surface area. Then the electrode was air-dried at room temperature.

To prepare Nf/Au/CSPE, $10 \mu \mathrm{L}$ of $0.5,1.0,1.5,2.0,2.5$, and 5.0\% Nf were deposited on the $\mathrm{Au} / \mathrm{CSPE}$ surface area. Then the electrode was air-dried at room temperature. Prior to use, the obtained modified electrode (Nf/Au/CSPE) was washed with distilled water.

As shown by our SEM studies [21,24], nanoparticles do not aggregate on the electrode surface, so the particle size on the surface was assumed to be the same as in the sol.

\subsection{Electrochemical Measurements}

Linear sweep voltammetry (LSV) was used in ordinary and derivative modes. The derivative curve presents simply differentiated initial voltammogram, dependence $\mathrm{d} I / \mathrm{d} E=\mathrm{f}(E)$ is recorded.

Recording of the anodic voltammograms was carried out using a phosphate buffer ( $\mathrm{pH} 5)$ at $v=50 \mathrm{mV} / \mathrm{s}$ in the range of potential $0.1-0.8$ or $0.1-0.9 \mathrm{~V}$. Derivative voltammograms were used due to poor separation of UA and AA signals in LSV. The measured signal is an amplitude of the derivative voltammogram ( $\mathrm{d} I / \mathrm{d} E$ curve). It is measured as shown in Figure 2 . The potential peak corresponds (as mathematical value) to the value of the derivative equal to zero. To exclude background currents the peak current potential is measured as half of the amplitude potential. This value is used for calculating UA and AA signals [27].

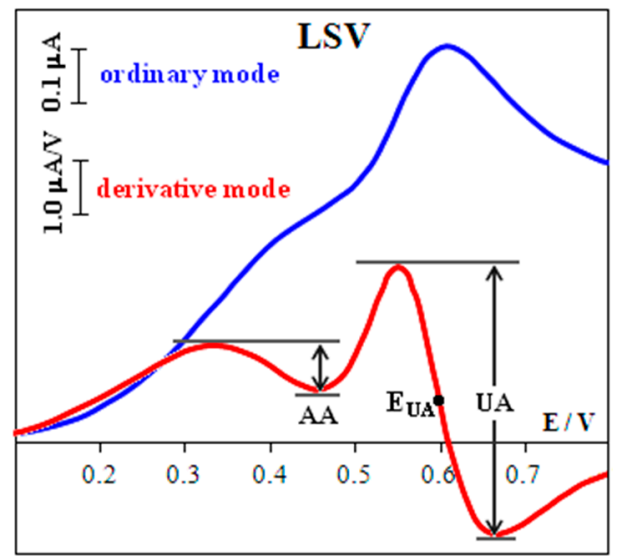

Figure 2. Derivative and ordinary anodic voltammograms of $0.1 \mathrm{mM}$ UA and $0.1 \mathrm{mM}$ AA mixtures at $\mathrm{Au}(5 \mathrm{~nm}) / \mathrm{CSPE}$. Background: PBS (pH 5), $v=50 \mathrm{mV} / \mathrm{s}$.

\subsection{Real Samples}

Frozen blood serum samples were provided by the clinical laboratory of Medical Technologies JSC, a multidisciplinary medical center. The results were compared with the data obtained in Medical Technologies JSC, via the method of BioSystems (Barcelona, Spain).

Milk samples from different manufacturers were purchased from local supermarkets and stored at $4{ }^{\circ} \mathrm{C}$ until the study. For analysis, aliquots of blood serum $(100 \mu \mathrm{L})$ or milk $(200 \mu \mathrm{L})$ were taken, which were introduced into an electrochemical cell containing $10 \mathrm{~mL}$ of phosphate buffer solution. Preliminary preparation of blood serum and milk samples was not required. 


\section{Results and Discussion}

\subsection{Comparison of Calculated and Experimental Data}

Figure 3 presents experimental voltammograms of UA oxidation on macro- and nanostructured electrodes. The correspondence of the shape of the experimental curves (Figure 3) and calculated one (Figure 1a) for a process of a certain type shows that a process of this type is taking place. The data presented in Figure 3 illustrates that UA oxidation on macro- and nanostructured electrodes is not complicated by the catalytic stage. The potential shift of UA electrooxidation on the nanostructured electrodes to the cathodic area vs. macroelectrodes testifies to the manifestation of nanoeffects (Table 1).

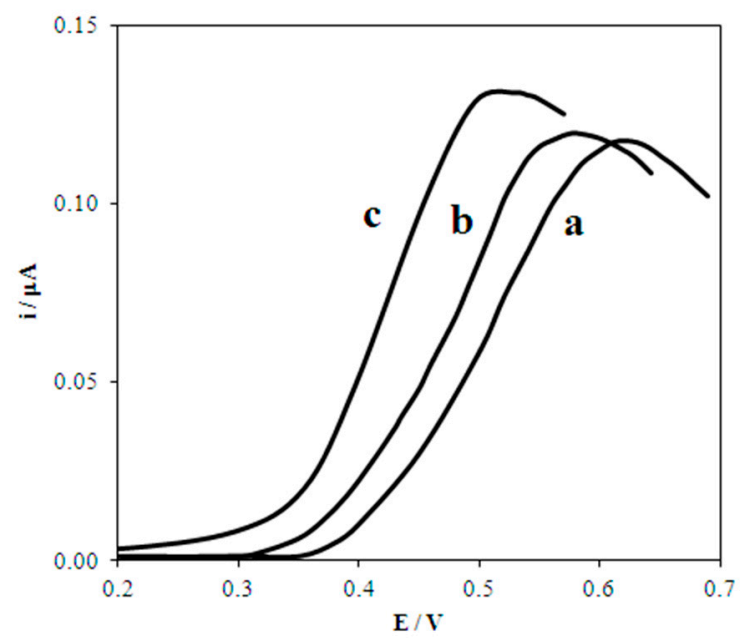

Figure 3. Experimental anodic voltammograms of $0.02 \mathrm{mM} \mathrm{UA}$ at GCE (a), Au(20nm)/GCE (b) and $\mathrm{Au}(5 \mathrm{~nm}) / \mathrm{GCE}(\mathrm{c})$. Background: PBS (pH 7), $v=50 \mathrm{mV} / \mathrm{s}$.

Table 1. Calculated and experimental parameters for voltammograms of UA electrooxidation on macroand nanostructured electrodes.

\begin{tabular}{cccccc}
\hline \multirow{2}{*}{ No. } & \multirow{2}{*}{ Electrode } & \multicolumn{2}{c}{ Calculated } & \multicolumn{2}{c}{ Experimental } \\
\cline { 3 - 6 } & & $\mathbf{I}, \boldsymbol{\mu A}$ & $\mathbf{E}_{\mathbf{1 / 2}}, \mathbf{V}$ & $\mathbf{I}, \boldsymbol{\mu A}$ & $\mathbf{E}_{\mathbf{1 / 2}}, \mathbf{V}$ \\
\hline 1 & $\mathrm{GCE}$ & 0.109 & 0.49 & 0.118 & 0.50 \\
2 & $\mathrm{Au}(20 \mathrm{~nm}) / \mathrm{GCE}$ & 0.111 & 0.47 & 0.120 & 0.46 \\
3 & $\mathrm{Au}(5 \mathrm{~nm}) / \mathrm{GCE}$ & 0.132 & 0.42 & 0.131 & 0.42 \\
4 & $\mathrm{Au}(14 \mathrm{~nm}) / \mathrm{Au}-\mathrm{bulk}$ & 0.409 & 0.46 & 0.393 & 0.47 \\
\hline
\end{tabular}

$\mathrm{E}_{1 / 2}$-half-wave potential of UA oxidation.

The smaller the size of the nanoparticles, immobilized on different electrodes, the greater the shift. This shift is caused by an increase in the Gibbs free energy of the nanostructured electrode $\left(\Delta G^{\circ}=7349.22,1837.31 \mathrm{~J} \mathrm{~mol}^{-1}\right.$ for Au 5, $20 \mathrm{~nm}$, respectively) as compared to the macroelectrode $\left(\Delta G^{\circ}=0 \mathrm{~J} \mathrm{~mol}^{-1}\right)$. These data indicate that nanoeffects in UA electrooxidation on gold nanoparticles are demonstrated. Nanoeffects are observed as a decrease in overvoltage of the electrode process. The effects are greater with a smaller size of nanoparticles, which is due to the contribution of the nanoparticles' Gibbs free energy to the kinetics of UA electrochemical oxidation. The reason is a lower energy barrier of the reaction [21].

The observed nanoeffects are independent of the nanoparticles synthesis method and the substrate nature. For example, the half-wave potential of UA oxidation on smaller nanoparticles $\left(A u_{\text {red }}=5 \mathrm{~nm}\right)$, obtained by citrate synthesis and immobilized on GCE, shifts by $50 \mathrm{mV}$ to the cathodic area as compared with larger nanoparticles $\left(A u_{\text {green }}=14 \mathrm{~nm}\right)$ obtained by "green" synthesis and immobilized on Au-bulk. 
Following the findings of the study, gold nanoparticles $\mathrm{Au}(5 \mathrm{~nm})$ were selected for developing the UA sensor.

\subsection{UA Oxidation in the Presence of $A A$ at the CSPE}

The individual signals of AA and UA oxidation on the CSPE are recorded at the potentials of 0.62 and $0.69 \mathrm{~V}$, respectively, in phosphate buffer solution $(\mathrm{pH} 5)$ with a potential difference $(\Delta E)$ of $0.07 \mathrm{~V}$ (Figure 4). In the simultaneous presence of AA and UA their signals overlap and form one broad signal (Figure 4), which increases with growing concentration of both AA and UA.

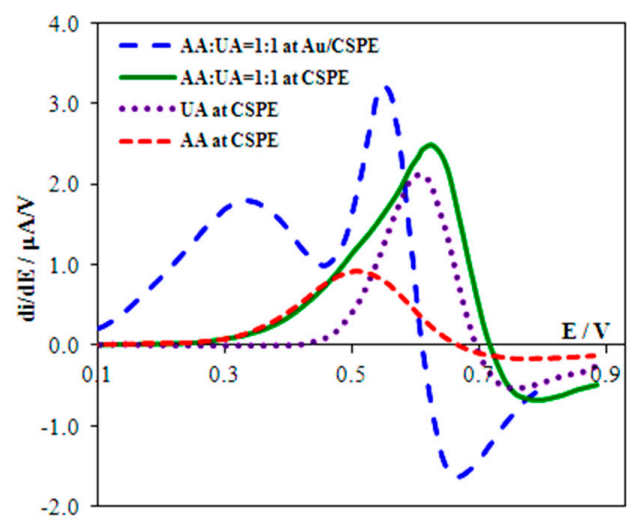

Figure 4. Derivative anodic voltammograms of $0.1 \mathrm{mM} \mathrm{UA}, 0.1 \mathrm{mM}$ AA at CSPE and their mixture at CSPE and Au(5nm)/CSPE. Background: PBS (pH 5), $v=50 \mathrm{mV} / \mathrm{s}$.

\subsection{Separating Signals of $U A$ and $A A$}

The signals of $\mathrm{AA}$ and $\mathrm{UA}$, corresponding to the equimolar ratio of their concentrations, are distinguished $(\Delta E=0.22 \mathrm{~V})$ on derivative voltammograms (Figure 4), and registered using $\mathrm{Au}(5 \mathrm{~nm}) / \mathrm{CSPE}$. A five-fold excess of AA is followed by overlapping of the signals. To avoid this phenomenon we protected the surface of the $\mathrm{Au}(5 \mathrm{~nm}) / \mathrm{CSPE}$ with Nafion. The maximum potential difference of oxidation of AA and UA $(\Delta E=0.34 \mathrm{~V})$ is observed at $2.5 \%$ Nafion concentration (Figure 5) at $\mathrm{pH}$ 5. This corresponds to the fact that, at $\mathrm{pH}$, the maximum permeability of Nafion for UA and minimum permeability for AA is attained [4]. The data given in Figure 6 shows that these are the best conditions for $\mathrm{UA}: \mathrm{AA}=1: 5$ separate signal registration $(\mathrm{pH}<5$ was not used because of the large background current in the potential range 0.0-0.9 V). In addition, Nafion stabilizes the gold nanoparticles on the electrode surface [28,29].

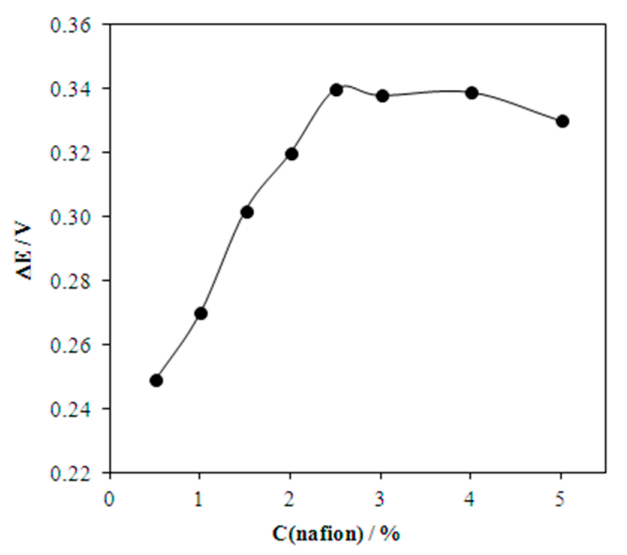

Figure 5. Effect of Nafion concentration on the difference of potentials of $0.1 \mathrm{mM}$ UA and $0.5 \mathrm{mM}$ AA oxidation at the Nf/ $\mathrm{Au}(5 \mathrm{~nm}) / \mathrm{CSPE}$. Background: PBS (pH 5), $v=50 \mathrm{mV} / \mathrm{s}$. 


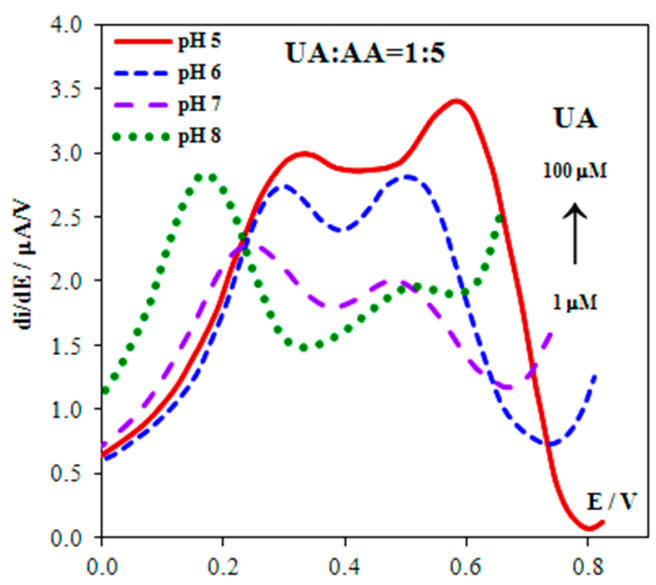

Figure 6. Derivative anodic voltammograms of $0.1 \mathrm{mM} \mathrm{UA}$ and $0.5 \mathrm{mM} \mathrm{AA}$ at the $2.5 \%$ $\mathrm{Nf} / \mathrm{Au}(5 \mathrm{~nm}) / \mathrm{CSPE}$ in background solution with different $\mathrm{pH}$.

\subsection{Analytical Characteristics and Real Samples Analysis}

Figure 7 shows the derivative voltammograms of UA oxidation with different concentrations at the $2.5 \% \mathrm{Nf} / \mathrm{Au}(5 \mathrm{~nm}) / \mathrm{CSPE}$. The magnitude of the UA signal is linearly dependent on UA concentration from $0.5 \mu \mathrm{M}$ to $600 \mu \mathrm{M}$, and is described by the regression equation $\mathrm{y}=0.0294 \mathrm{x}+0.0359$ with a correlation coefficient $\mathrm{R}^{2}=0.9966$. The detection limit of UA at the $2.5 \% \mathrm{Nf} / \mathrm{Au}(5 \mathrm{~nm}) / \mathrm{CSPE}$ is $0.25 \mu \mathrm{M}$. The relative standard deviation of the signal for $5 \mu \mathrm{M}$ UA is $1.9 \%$.

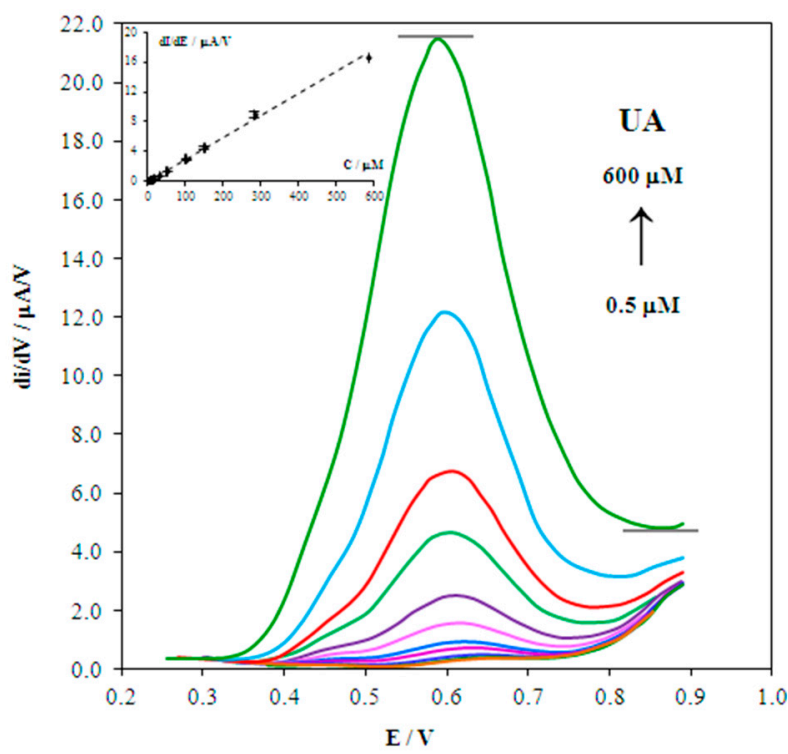

Figure 7. Derivative anodic voltammograms with increasing concentrations of UA $(0.5-600 \mu \mathrm{M})$ at the $2.5 \% \mathrm{Nf} / \mathrm{Au}(5 \mathrm{~nm}) / \mathrm{CSPE}$. Inset: corresponding calibration curve $\mathrm{d} I / \mathrm{d} E=\mathrm{f}(\mathrm{C})$. Background: PBS $(\mathrm{pH}), v=50 \mathrm{mV} / \mathrm{s}$.

A 100-fold excess of glucose and urea, a 70-fold of creatinine, a 10-fold excess of tryptophan, and a five-fold excess of AA do not interfere with UA determination at the $2.5 \% \mathrm{Nf} / \mathrm{Au}(5 \mathrm{~nm}) / \mathrm{CSPE}$ (Table 2). 
Table 2. Interference of some substances with UA signal (The signal caused by $3 \mu \mathrm{M} U A$ is taken as $100 \%)$.

\begin{tabular}{ccc}
\hline Interfering Substance & Concentration, $\boldsymbol{\mu M}$ & Changing Signal \\
\hline AA & 15 & $+1.3 \%$ \\
L-Triptophan & 30 & $-2.6 \%$ \\
Urea & 300 & $+2.8 \%$ \\
Glucose & 300 & $+4.8 \%$ \\
Creatinine & 200 & $-4.4 \%$ \\
\hline
\end{tabular}

Analytical characteristics of the $2.5 \% \mathrm{Nf} / \mathrm{Au}(5 \mathrm{~nm}) / \mathrm{CSPE}$ remain stable for a month after storage at room temperature.

Analytical characteristics of UA determination with the use of the proposed sensor and other modified CSPEs are displayed in Table 3. The advantages of the developed sensor are as follows: it does not require time-consuming preparatory adsorption concentration [11-13] or complex and expensive equipment for FIA [16,18], does not contain rapidly degrading enzymes [18,19], and does not require long preparation of the modifier and modification [14,17]. Unlike most of the known modified CSPE [11,13,14,17-19], used in the urine analysis only, the developed sensor enables the analysis of blood serum, and also in a broader linear concentration range than in [15]. Another important advantage of the developed sensor is that it allows us to determine UA in milk without pre-separation and pre-concentration, which none of the existing sensors do.

Table 3. Analytical characteristics of UA determination with the use of different modified CSPEs.

\begin{tabular}{|c|c|c|c|c|c|c|}
\hline Electrode & $\begin{array}{c}\text { Linear } \\
\text { Range, } \\
\mu \mathrm{M}\end{array}$ & $\begin{array}{c}\text { Limit of } \\
\text { Detection, } \mu \mathrm{M}\end{array}$ & $\begin{array}{c}\text { Conditions of Signal } \\
\text { Formation }\end{array}$ & $\mathrm{pH}$ & Real Sample & Ref. \\
\hline MWCNTs/CSPE & $1-100$ & 0.86 & $\begin{array}{c}t_{\mathrm{acc}}=300 \mathrm{~s}, \text { open circuit } \\
\text { potential LSV }\end{array}$ & 5 & urine & [11] \\
\hline PAA-MWCNTs/CSPE & $0.5-30$ & 0.458 & $\begin{array}{c}t_{\mathrm{acc}}=1500 \mathrm{~s}, \text { open } \\
\text { circuit potential DPV }\end{array}$ & 7.5 & suppotingelectrolyte & [12] \\
\hline CS-SWCNTs-IL/CSPE & $0.5-1000$ & 0.17 & $\begin{array}{c}t_{\mathrm{acc}}=100 \mathrm{~s}, E_{\mathrm{acc}}=-0.1 \\
\text { V LSV }\end{array}$ & 2.4 & urine & [13] \\
\hline Au-nps/CSPE & $0.0005-5000$ & 0.0005 & FIA, Am & 1 & suppotingelectrolyte & [16] \\
\hline UOx-poly(4-ASA)-PB-CSPE & $10-200$ & 3 & FIA, Am & 8.27 & urine & [18] \\
\hline PC-UOx-CA-CoPC-CSPE & $15-250$ & 15 & ChAm & 9.2 & urine & [19] \\
\hline $\mathrm{GO} / \mathrm{Fe}_{3} \mathrm{O}_{4} @ \mathrm{SiO}_{2} / \mathrm{CSPE}$ & $0.75-300$ & 0.57 & DPV & 7 & urine & [17] \\
\hline rGO-CSPE & $10-3000$ & 0.35 & DPV & 7 & urine & [14] \\
\hline$\beta-\mathrm{CD} / \mathrm{rGO} / \mathrm{CSPE}$ & $0.08-150$ & 0.026 & DPV & 7 & blood serum & [15] \\
\hline $2.5 \% \mathrm{Nf} / \mathrm{Au}(5 \mathrm{~nm}) / \mathrm{CSPE}$ & $0.5-600$ & 0.25 & LSV & 5 & $\begin{array}{l}\text { blood serum, } \\
\text { milk }\end{array}$ & his work \\
\hline \multicolumn{7}{|c|}{ 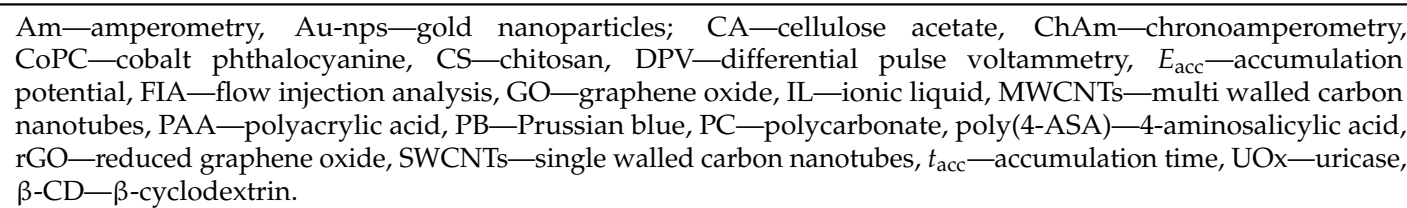 } \\
\hline
\end{tabular}

Table 4 shows the analysis results of blood serum samples. It is apparent from the table that recovery does not exceed $110 \%$, which suggests acceptable reliability of UA determination in blood serum samples obtained using $2.5 \% \mathrm{Nf} / \mathrm{Au}(5 \mathrm{~nm}) / \mathrm{CSPE}$. UA found in all samples of blood serum corresponds to the medical norm $(0.15-0.42 \mathrm{mM})$. 
Table 4. Analysis results of blood serum samples using $2.5 \% \mathrm{Nf} / \mathrm{Au}(5 \mathrm{~nm}) / \operatorname{CSPE}(n=3, P=0.95)$.

\begin{tabular}{ccccc}
\hline Sample & UA in Serum, $\mathbf{m M}$ & UA Added, $\mathbf{~ m M}$ & $\begin{array}{c}\text { UA Found, mM } \\
\text { (Sample + Additive) }\end{array}$ & Recovery, \% \\
\hline Serum 1 & 0.36 & 0.50 & $0.91 \pm 0.05$ & 109 \\
Serum 2 & 0.24 & 0.30 & $0.57 \pm 0.12$ & 110 \\
Serum 3 & 0.58 & 0.25 & $0.84 \pm 0.09$ & 103 \\
Serum 4 & 0.21 & 0.30 & $0.54 \pm 0.06$ & 110 \\
Serum 5 & 0.16 & 0.30 & $0.49 \pm 0.07$ & 107 \\
\hline
\end{tabular}

The comparison of the results of electrochemical UA determination by using $2.5 \%$ $\mathrm{Nf} / \mathrm{Au}(5 \mathrm{~nm}) / \mathrm{CSPE}$ with the results of the enzymatic spectrophotometric method demonstrated a good correlation $\left(R^{2}=0.993\right)$ (Figure 8$)$.

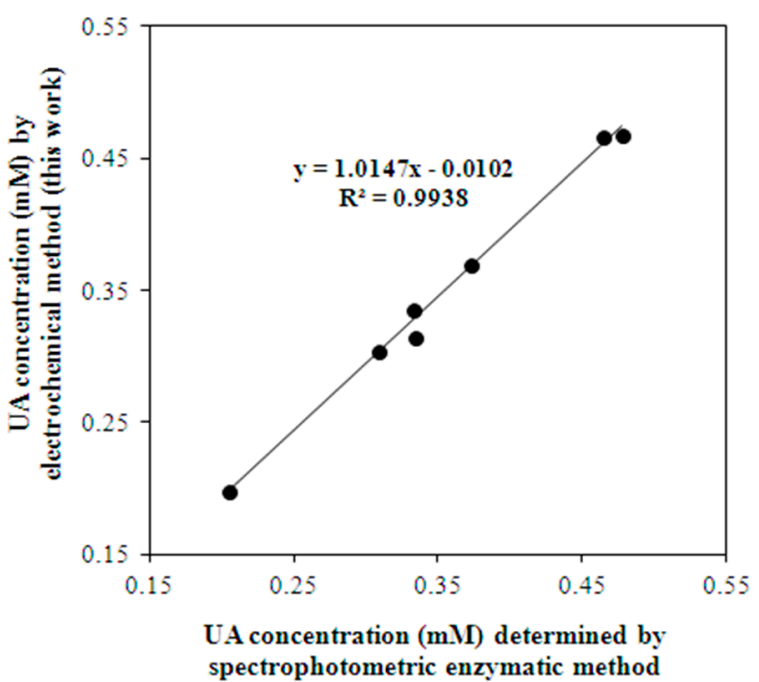

Figure 8. Correlation between results of UA determination in blood serum samples obtained by the enzymatic spectrophotometric method and the proposed electrochemical method.

The proposed sensor was tested by adding given amounts of analyte standards into the milk samples. The percentage recoveries were found to be $96.5-101.5 \%$ as presented in Table 5 . $\mathrm{S}_{\mathrm{r}}$ does not exceed $2.5 \%$.

Table 5. Analysis results of milk samples using $2.5 \% \mathrm{Nf} / \mathrm{Au}(5 \mathrm{~nm}) / \mathrm{CSPE}(n=3, p=0.95)$.

\begin{tabular}{ccccc}
\hline Sample & Added, $\boldsymbol{\mu M}$ & Found, $\boldsymbol{\mu M}$ & Recovery, $\%$ & Sr, $\%$ \\
\hline Sample 1 & 20.0 & 20.3 & 101.5 & 2.5 \\
Sample 2 & 20.0 & 19.9 & 99.5 & 1.6 \\
Sample 3 & 20.0 & 19.3 & 96.5 & 1.9 \\
\hline
\end{tabular}

\section{Conclusions}

The mathematical modeling and experimental studies have shown that the process of UA electrooxidation with gold nanoparticles is not complicated by catalytic stages. This conclusion proves that the common view that nanoparticles serve as catalysts in electrode processes is not convincing. The data obtained in this paper show that the role of nanoparticles is to contribute the Gibbs free energy to the reaction kinetics. 
The nanoeffects of the particles obtained by citrate and "green" synthesis are exhibited in a lower UA oxidation potential, and it is greater with a smaller size of gold nanoparticles. These findings allow us to justify the choice of gold nanoparticles $\mathrm{Au}(5 \mathrm{~nm})$ for developing an UA sensor.

It was shown for the first time that the CSPE, modified with $5 \mathrm{~nm}$ gold nanoparticles and $2.5 \%$ Nafion, and pH 5 background electrolyte ensures selective and sensitive determination of UA in the presence of AA. The combination of the properties of nanoparticles and Nafion as a molecular sieve at the selected $\mathrm{pH} 5$ phosphate buffer solution has significantly improved the resolution of the sensor compared to unmodified CSPE. The developed sensor with a linear range of $0.5-600 \mu \mathrm{M}$ and a detection limit of $0.25 \mu \mathrm{M}$ has been successfully applied to determining UA in blood serum and milk samples without prior preparation of the electrode surface, time-taking modification and additional UA concentration, and the use of complex equipment and recording, which allows us to recommend the proposed sensor for nonlaboratory analysis. The correctness of the analysis results has been confirmed by a good correlation with the enzymatic spectrophotometric analysis $\left(R^{2}=0.9938\right)$ and the "added-found" technique (recovery close to $100 \%$ ).

Acknowledgments: The research was financially supported by RFBR (Project \#17-03-00679A). The authors are grateful to Medical Technologies JSC for providing blood serum samples and providing their measurements results.

Author Contributions: N.S. conceived and designed the experiments; M.B. performed the experiments; L.G. developed mathematical model and made calculations; N.S. and B.K. analyzed the data and wrote the paper.

Conflicts of Interest: The authors declare no conflict of interest.

\section{References}

1. Gwag, H.B.; Yang, J.H.; Park, T.K.; Song, Y.B.; Hahn, J.-Y.; Choi, J.-H.; Lee, S.H.; Gwon, H.-C.; Choi, S.-H. Uric acid level has a U-shaped association with clinical outcomes in patients with vasospastic angina. J. Korean Med. Sci. 2017, 32, 1275-1280. [CrossRef] [PubMed]

2. Shiozawa, A.; Buysman, E.K.; Korrer, S. Serum uric acid levels and the risk of flares among gout patients in a US managed care setting. Curr. Med. Res. Opin. 2017, 33, 117-124. [CrossRef] [PubMed]

3. Wang, C.; Du, J.; Wang, H.; Zou, C.; Jiang, F.; Yang, P.; Du, Y. A facile electrochemical sensor based on reduced graphene oxide and Au nanoplates modified glassy carbon electrode for simultaneous detection of ascorbic acid, dopamine and uric acid. Sens. Actuators B 2014, 204, 302-309. [CrossRef]

4. Zen, J.-M.; Jou, J.-J.; Ilangovan, G. Selective voltammetric method for uric acid detection using pre-anodized Nafion-coated glassy carbon electrodes. Analyst 1998, 123, 1345-1350. [CrossRef]

5. Filik, H.; Avan, A.A.; Aydar, S. Simultaneous detection of ascorbic acid, dopamine, uric acid and tryptophan with Azure A-interlinked multi-walled carbon nanotube/gold nanoparticles composite modified electrode. Arabian J. Chem. 2016, 9, 471-480. [CrossRef]

6. Dorraji, P.S.; Jalali, F. Novel sensitive electrochemical sensor for simultaneous determination of epinephrine and uric acid by using a nanocomposite of MWCNTs-chitosan and gold nanoparticles attached to thioglycolic acid. Sens. Actuators B 2014, 200, 251-258. [CrossRef]

7. Liu, X.; Xie, L.; Li, H. Electrochemical biosensor based on reduced graphene oxide and Au nanoparticles entrapped in chitosan/silica sol-gel hybrid membranes for determination of dopamine and uric acid. J. Electroanal. Chem. 2012, 682, 158-163. [CrossRef]

8. Yang, C.Y.; Chen, S.-M.; Palanisamy, S. Simultaneous electrochemical determination of dopamine, uric acid, tryptophan on electropolymerized aminothiazole and gold nanoparticles modified carbon nanotubes modified electrode. Int. J. Electrochem. Sci. 2016, 11, 2638-2649. [CrossRef]

9. Tian, X.; Cheng, C.; Yuan, H.; Du, J.; Xiao, D.; Xie, S.; Choi, M.M.F. Simultaneous determination of L-ascorbic acid, dopamine and uric acid with gold nanoparticles- $\beta$-cyclodextrin-graphene-modified electrode by square wave voltammetry. Talanta 2012, 93, 79-85. [CrossRef] [PubMed]

10. Li, F.; Cha, Y.; Yuan, R.; Li, X.; Yang, Y. Simultaneous determination of ascorbic acid, dopamine and uric acid based on gold nanoparticles-PTCA-Cys composites modified electrodes. J. Chin. Chem. Soc. 2015, 62, 739-746. [CrossRef] 
11. Fanjul-Bolado, P.; Santos, D.H.; Montoya, V.M.; Costa-García, A. Uric Acid Determination by Adsorptive Stripping Voltammetry on Multiwall Carbon Nanotubes Based Screen-Printed Electrodes. Electroanalysis 2015, 27, 1276-1281. [CrossRef]

12. Huang, S.-H.; Liao, H.-H.; Chen, D.-H. Simultaneous determination of norepinephrine, uric acid, and ascorbic acid at a screen printed carbon electrode modified with polyacrylic acid-coated multi-wall carbon nanotubes. Biosens. Bioelectron. 2010, 25, 2351-2355. [CrossRef] [PubMed]

13. Nagles, E.; García-Beltrán, O.; Calderón, J.A. Evaluation of the usefulness of a novel electrochemical sensor in detecting uric acid and dopamine in the presence of ascorbic acid using a screen-printed carbon electrode modified with single walled carbon nanotubes and ionic liquids. Electrochim. Acta 2017, 258, 512-523. [CrossRef]

14. Kanyong, P.; Rawlinson, S.; Davis, J. A Voltammetric Sensor Based on Chemically Reduced Graphene Oxide-Modified Screen-Printed Carbon Electrode for the Simultaneous Analysis of Uric Acid, Ascorbic Acid and Dopamine. Chemosensors 2016, 4, 25. [CrossRef]

15. Qin, Q.; Bai, X.; Hua, Z.L. Electropolymerization of a conductive beta-cyclodextrin polymer on reduced graphene oxide modified screen-printed electrode for simultaneous determination of ascorbic acid, dopamine and uric acid. J. Electroanal. Chem. 2016, 782, 50-58. [CrossRef]

16. Shaidarova, L.G.; Chelnokova, I.A.; Il'ina, M.A.; Leksina, Y.A.; Gedmina, A.V.; Budnikov, H.K. Amperometric Detection of Creatinine and Uric Acid at the Screen-Printed Electrode Modified By Gold Nanoparticles in Flow-Injection Analysis. Res. J. Pharm. Biol. Chem. Sci. 2015, 6, 1629-1635.

17. Beitollahi, H.; Nejad, F.G.; Shakeri, S. GO/Fe3O4@SiO2 core-shell nanocomposite-modified graphite screen-printed electrode for sensitive and selective electrochemical sensing of dopamine and uric acid. Anal. Methods 2017, 9, 5541-5549. [CrossRef]

18. Da Cruz, F.S.; Paula, F.D.S.; Franco, D.L.; dos Santos, W.T.P.; Ferreira, L.F. Electrochemical detection of uric acid using graphite screen-printed electrodes modified with Prussian blue/poly(4-aminosalicylic acid)/Uricase. J. Electroanal. Chem. 2017 806, 172-179. [CrossRef]

19. Kanyong, P.; Pemberton, R.M.; Jackson, S.K.; Hart, J.P. Development of a sandwich format, amperometric screen-printed uric acid biosensor for urine analysis. Anal. Biochem. 2012, 428, 39-43. [CrossRef] [PubMed]

20. Malakhova, N.A.; Mysik, A.A.; Saraeva, S.Y.; Stozhko, N.Y.; Uimin, M.A.; Ermakov, A.E.; Brainina, K.Z. A Voltammetric Sensor on the Basis of Bismuth Nanoparticles Prepared by the Method of Gas Condensation. J. Anal. Chem. 2010, 65, 640-647. [CrossRef]

21. Brainina, K.Z.; Stozhko, N.Y.; Bukharinova, M.A.; Galperin, L.G.; Vidrevich, M.B.; Murzakaev, A.M. Mathematical modelling and experimental data of the oxidation of ascorbic acid on electrodes modified by nanoparticles. J. Solid State Electrochem. 2016, 20, 2323-2330. [CrossRef]

22. Brainina, K.Z.; Galperin, L.G.; Bukharinova, M.A.; Stozhko, N.Y. Mathematical modeling and experimental study of electrode processes. J. Solid State Electrochem. 2014, 19, 599-606. [CrossRef]

23. Ardakani, M.M.; Akrami, Z.; Kazemian, H.; Zare, H.R. Electrocatalytic characteristics of uric acid oxidation at graphite-zeolite-modified electrode doped with iron (III). J. Electroanal. Chem. 2006, 586, 31-38. [CrossRef]

24. Brainina, K.Z.; Galperin, L.G.; Vikulova, E.V.; Stozhko, N.Y.; Murzakaev, A.M.; Timoshenkova, O.R.; Kotov, Y.A. Gold nanoparticles electrooxidation: Comparison of theory and experiment. J. Solid State Electrochem. 2011, 15, 1049-1056. [CrossRef]

25. Simic, M.G.; Jovanovic, S.V. Antioxidant Mechanisms of Uric Acid. J. Am. Chem. Soc. 1989, 111, 5778-5782. [CrossRef]

26. Chemical Handbook, 2nd ed.; Nikolskii, B.P. (Ed.) Chemistry: Moscow, Russia, 1966; Volume 1, p. 1006.

27. Piankova, L.A.; Malakhova, N.A.; Stozhko, N.Y.; Brainina, K.Z.; Murzakaev, A.M.; Timoshenkova, O.R. Bismuth nanoparticles in adsorptive stripping voltammetry of nickel. Electrochem. Commun. 2011, 13, 981-984. [CrossRef] 
28. Foxx, D.; Kalu, E.E. Amperometric biosensor based on thermally activated polymer-stabilized metal nanoparticles. Electrochem. Commun. 2007, 9, 584-590. [CrossRef]

29. Gupta, G.; Sharma, S.; Mendes, P.M. Nafion-stabilised bimetallic Pt-Cr nanoparticles as electrocatalysts for proton exchange membrane fuel cells (PEMFCs). RSC Adv. 2016, 6, 82635-82643. [CrossRef] [PubMed] 